\title{
Surgical Removal of Shaving Blade from Stomach of Dog
}

\author{
Mithilesh Kumar ${ }^{1 *}$, Ranbir Kumar Sinha ${ }^{2}$ and Deepak Kumar ${ }^{3}$ \\ ${ }^{1}$ Veterinary Surgery and Radiology, ${ }^{2}$ Veterinary Medicine, ${ }^{3}$ Veterinary Pathology \\ Bihar Veterinary College, Patna-800014, India \\ *Corresponding author
}

Keywords

Dog, History, Radiograph and Anaesthesia

Article Info

Accepted:

20 February 2020

Available Online:

10 March 2020

\section{A B S T R A C T}

A 2 years old Labrador dog was coming with history of ingestion of a new covered shaving blade immediately falling with owner's hand during his shaving. Owner came to clinics after one day of the incident but any food was not given in that period, kept only on water. There were no any clinical signs observed in that period. Dog was normal. Lateral radiography was taken which revealed radio-opaque shaving blade in the stomach area. Solid food was not given after ingestion of shaving till surgical intervention. Surgical correction was planned to remove the shaving blade from the stomach next day. General anaesthesia was used and shaving blade was removed. The stomach was sutured with vicryl no. 1/0 in continuous lumbert and cushing pattern in double layer. Post-operatively administration of antibiotics, analgesics and regular dressing of wound was done and dog recovered uneventfully.

\section{Introduction}

The dog was very active and playing habits and sometime taking non-food objects leading to gastric foreign body syndrome (Tripathi et al., 2010). Gastro-intestinal foreign bodies are challenging and difficult cases to manage and their treatment its location and degree of obstruction. Foreign body fixed with tissue and sharp foreign bodies is not recommended endoscopic examination. Sharp foreign body might be risk of perforation of the organ and anchor in pylorus may require surgical extraction (Karen M. Tobias, 2006) Veterinary medicine 1234). Indiscriminate feeding objects are stones, bones, coins, balls, clothes, rags, metallic spoons, rubber nipples and magnets has been reported in dogs (Monindroo et al., 2006, Hayes 2009, Rossmeissi et al., 2011). Playing habits and more activity of young dog are responsible for ingestion and subsequent lodgement of foreign body in GIT (Koike et al., 1981, Applewhite et al., 2002, Han et al., 2008). 


\section{Case and Diagnosis}

A 2years old male Labrador dog weighing 35 $\mathrm{kg}$ presented in the clinics with history of ingestion of shaving blade in one day before and animal was kept without foods and water. The activity of dog was normal. The temperature, heart rate and respiration rate were not changed. Lateral radiograph showed picture of shaving blade with radio-opaque density in stomach area (Fig. 1). Animal was stabilized with IV DNS-5\%. Next day surgical removal was planned.

\section{Surgical treatment}

The general anaesthesia in dog was in combination in of atropine $0.04 \mathrm{mg} / \mathrm{kg}$ body weight, xylazine $1 \mathrm{mg} / \mathrm{kg}$ body weight and ketamine $\quad 5 \mathrm{mg} / \mathrm{kg}$ body weight intramuscularly. Dog was maintained anaesthetic condition by repeated dose of ketamine intermittently with intramuscularly route. Animal was restrained in dorsal recumbency and behind the post-xiphoid area of abdomen was shaved and prepared aseptically for surgery. Abdominal cavity approached by incision just behind postxiphoid in direction along linea alba Stomach was exteriorized. Least vascular area of stomach was incised and stomach kept in outside by stay suture. Shaving blade was explored and removed outside by using alies forceps (Fig. 1) The stomach was sutured by lambert suture followed by cushing to prevent leakage with vicryl 1/0. Muscle and peritoneum were sutured in simple interrupted pattern with vicryl 1/0. Silk was used to suture the skin with horizontal pattern. Dog was treated post-operatively with ceftriazone \& sulbactum inj. @ $10 \mathrm{mg} / \mathrm{kg}$ body weight I.M. once daily for 8 days and inj. Meloxicam @ $0.2 \mathrm{mg} / \mathrm{kg}$ body weight i.m. once daily for three days.Food and water were not given to animal for 4 days. In this period animal was kept RL $250 \mathrm{ml}$ and DNS 5\% $250 \mathrm{ml}$ intravenously twice daily. Multivitamin inj. $2 \mathrm{ml}$ (CB12) was mixed in the fluid for three days. Glucose mixed with water was given from $4^{\text {th }}$ day. Milk was allowed from $7^{\text {th }}$ day onward. Suture removed on $12^{\text {th }}$ postoperative day. Animal recovered uneventfully

\section{Results and Discussion}

Foreign body feeding habit of the dog might be leading to foreign body syndrome at any age of the dog showed gastric obstruction but more commonly found in younger dog (Rosmussen, 2008). There are many reasons for intestinal obstruction in dog like foreign body, neoplasia and peritonitis. In this case recovered recently ingested shaving blade that may cause obstruction and injury to the stomach and intestine further because of sharp edge of shaving blade. Case was recent. all physical parameter was normal and not showing any symptoms. Foreign body found in fundus of stomach was not showing any symptom. If they located in pyloric area of stomach, gastric emptying may be impaired (Uma Rani et al., 2010). Gastric outflow obstruction, gastric perforation or systemic illness as breakdown and absorption of foreign body might be casual by foreign body (Patil et al., 2010). Lateral radiograph of abdomen showed radio-opaque clear picture of shaving blade in the stomach area. Gastrotomy is performed for removal of foreign bodies and stomach tumours in treatment of stomach problems (Haragopal and Suresh Kumar 1996). Early diagnosis and surgery of the organ are important as the chance of perforation and peritonitis increase with delay in surgery. Removal of foreign bodies from the intestine and stomach with enterotomy and gastrotomy are the standard technique. 


\section{Int.J.Curr.Microbiol.App.Sci (2020) 9(3): 2710-2714}

Fig.1 Removal of shaving blade during gastrotomy

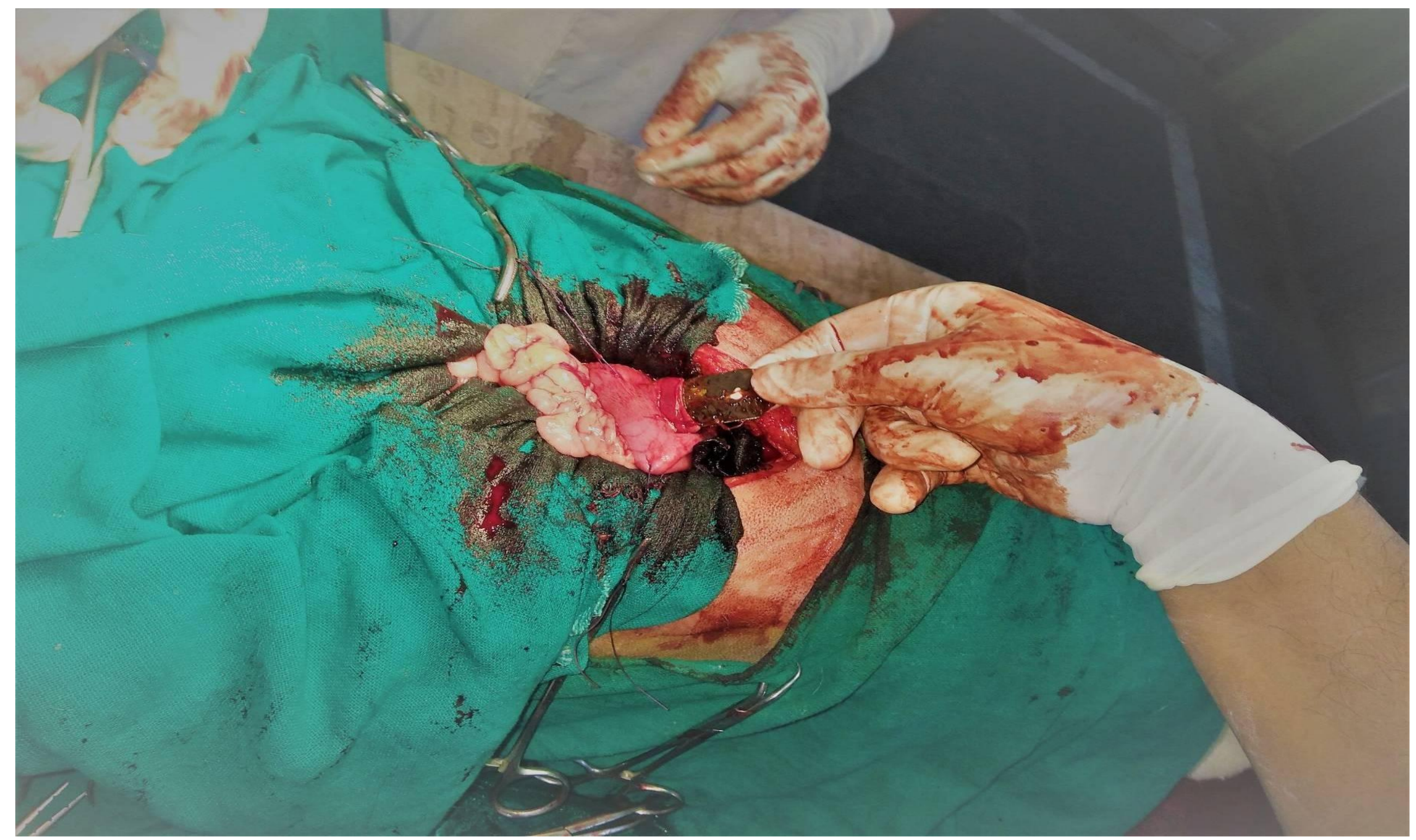


Int.J.Curr.Microbiol.App.Sci (2020) 9(3): 2710-2714

Fig.2 Radiograph indicate shaving blade in stomach

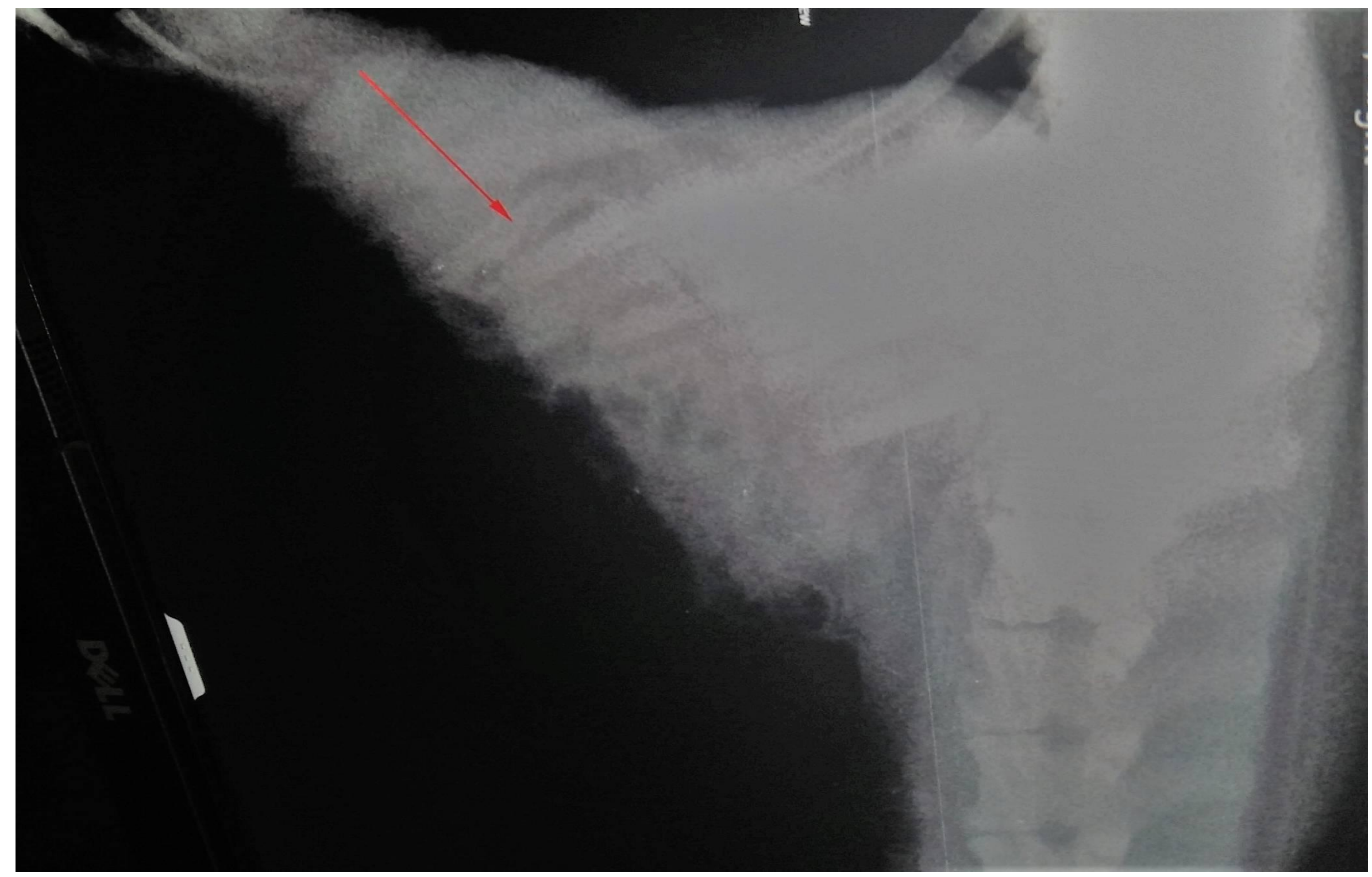




\section{References}

Applewhite, A. A. et.al (2002) Compendium on continuing education for the Practising Veterinarian 24: 110-127.

Haragopal, V. And Suresh Kumar, R.V. (1996). Surgical removal of a fish bone from the canine esophagus through gastrotomy. Can. Vet. J. 37:156.

Han, T.S. et al., (2008) J Bomed Res 9: 5558.

Hayes, G. (2009) J. Small Ani. Pract. 50: 576583.

Koike, T. Et al., (1981) Japanese J Vet Res 29: 8-15.

Mohindroo, J. Et al., (2006) Indian J Vet Res 27: $35-36$.
Patil, D.K. and Mehraj U Din Dar. (2010). Gastric foreign bodies in dogs. A report of five cases. Intas Polivet. 11 (11): 297-298.

Rossmeissi, E.M. et al., (2011) J Amer Ani Hospital Assoc 47: 56-59.

Tripathi, A.K., Soodan, J.S. and Kushwaha, R.B. (2010). Gastric foreign body syndrome in a Golden Retriever dog. IntasPolivet 11 (11): 305-306.

Tobias K M (2006) Veterinary Medicine 1234.

Uma Rani, R., Vairavasamy, K. And Muruganandan, B. (2010). Surgical management of gastric foreign Bodies in pups. IntasPolivet, 11(11): 302-303.

\section{How to cite this article:}

Mithilesh Kumar, Ranbir Kumar Sinha and Deepak Kumar. 2020. Surgical Removal of Shaving Blade from Stomach of Dog. Int.J.Curr.Microbiol.App.Sci. 9(03): 2710-2714.

doi: https://doi.org/10.20546/ijcmas.2020.903.309 